\title{
Construa você mesmo: sensor de chuva
}

Do it yourself: rain sensor

\author{
Francisco Catelli ${ }^{* 1}$, Alexandre Mesquita ${ }^{1}$ \\ ${ }^{1}$ Universidade de Caxias do Sul, Programa de Pós Graduação em Ensino de Ciências e Matemática, Caxias do Sul, RS, Brasil
}

Recebido em 01 de Junho, 2018. Revisado em 05 de Julho, 2018. Aceito em 16 de Julho, 2018

\begin{abstract}
É descrita a construção e exploração de um dispositivo didático simples, destinado à detecção de gotas de água (chuva), a partir da reflexão interna total da luz. O dispositivo é de construção simples, baixo custo, e pode ser empregado mesmo em ambientes com grande número de alunos.
\end{abstract}

Palavras-chave: sensor de chuva, reflexão interna total, óptica.

The construction and operation of a simple didactic device is presented, designed to detect water droplets (rain), from the total internal reflection of light. The device is simple to construct, low cost, and can be used even in environments with large numbers of students.

Keywords: rain sensor, total internal reflection, optics.

\section{Introdução}

O século XVI foi prolífico no campo das descobertas em óptica. No que diz respeito ao tema desse trabalho, a refração, lunetas, óculos e microscópios foram estudados e aperfeiçoados. Wilebrod Snell $(1591-1626)$ é tido como formulador, em bases empíricas, da lei da refração, em 1621; René Descartes $(1596$ - 1650) foi o primeiro a publicar a lei da refração na sua formulação em senos, hoje familiar para praticamente todos os estudantes de ótica ao longo do mundo [1]. A formulação em senos é a que segue:

$$
n_{1} \sin \theta_{i}=n_{2} \sin \theta_{t}
$$

onde $n_{1}$ e $n_{2}$ são os índices de refração dos dois meios (ver também o apêndice $\mathrm{A}$ ). $\mathrm{O}$ meio 1 contém o raio que incide na interface de separação dos dois meios; $\theta_{i}$ é o ângulo que o raio incidente faz com a direção normal ao plano de separação dos dois meios, e $\theta_{t}$ é o ângulo que o raio transmitido faz com a direção normal. Se for considerada também a reflexão, o raio refletido aparece sob um ângulo $\theta_{r}$, numericamente igual a $\theta_{i}$. Convém notar que os três raios, o incidente, o refletido e o refratado estão todos contidos num mesmo plano, o chamado "plano de incidência".

Quando $n_{1}$ é maior que $n_{2}$, pode ocorrer um fenômeno chamado "reflexão interna total". A ideia básica é a que segue: quando um raio incide de um meio mais refringente para outro, menos refringente, o ângulo de refração será sempre maior que o ângulo de incidência. Nessas condições, haverá um ângulo de incidência para o qual o ângulo de refração será de $90^{\circ}$. O raio refletido, como já observado, formará com a direção normal o mesmo

*Endereço de correspondência: fcatelli@ucs.br ângulo do raio incidente. Então, para ângulos de incidência maiores que esse ângulo, costumeiramente chamado de ângulo crítico, não haverá mais refração, ocorrendo apenas reflexão [2]. A título de exemplo: para $n_{1}=1,5$, e $n_{2}=1$, o ângulo crítico é $41,8^{\circ}$ (veja a imagem central da figura 1).

Considere agora a seguinte situação: se o meio 1 for acrílico (índice de refração igual a 1,5, aproximadamente), e o ângulo de incidência for escolhido como sendo igual a $45^{\circ}$ (será explicado a seguir o porquê dessa escolha), ocorrerá, como explicado acima, uma reflexão interna total, dado que esse ângulo de incidência $\left(45^{\circ}\right)$ excede o ângulo crítico, de $41,8^{\circ}$. Se segundo meio, que era o ar $\left(n_{2}=1\right)$, passar a ser água $\left(n_{2}=1,33\right)$, o raio refratado, que antes não existia, agora existirá, e aparecerá sob um ângulo $\theta_{t}=52,9^{\circ}$ (veja a figura 2).Esse é o fundamento físico do sensor de chuva óptico, explorado nessa trabalho. Há referências a sensores de chuva que remontam à década de 50 do século passado, e na sua maior parte são baseados no princípio óptico aqui descrito, a reflexão interna total [3]. Uma descrição, com viés técnico, de sensores de chuva automotivos pode ser encontrada, por exemplo, em Byung, Young e Lee [4], onde o mesmo método aqui descrito é utilizado para estabelecer um controle da velocidade do limpador de para-brisas em função do tamanho das gotas de chuva que incidem no vidro dianteiro do automóvel.

Com base no exposto, a proposta desse trabalho é a que segue: um raio de luz (um feixe estreito e colimado de laser) incide numa interface acrílico - ar, segundo um ângulo ligeiramente superior ao ângulo limite. $\mathrm{O}$ ângulo de $45^{\circ}$ é favorável, dado que é possível encontrar no mercado (ou no laboratório de Física, caso esteja disponível) prismas de acrílico com esse ângulo, a um 

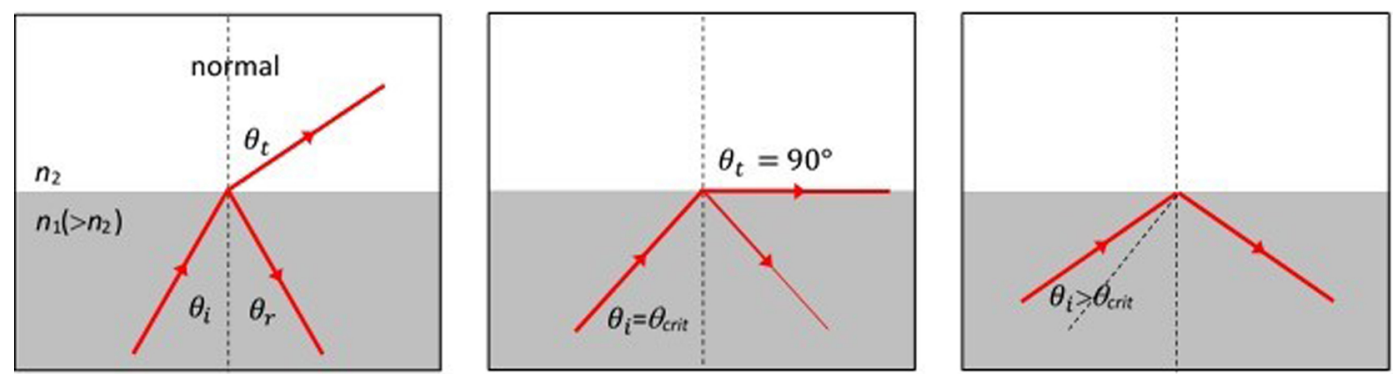

Figura 1: Na figura à esquerda, o ângulo de incidência é menor que o ângulo crítico. São representados o raio incidente (que forma um ângulo $\theta_{\mathrm{i}}$ com a normal), o raio refletido $\left(\theta_{r}=\theta_{\mathrm{i}}\right)$ e o raio refratado ou transmitido (que forma um ângulo $\theta_{\mathrm{t}}$ com a normal). Na figura central, $\theta_{t}=90^{\circ}$, e $\theta_{\mathrm{i}}$ passa a ser denominado de ângulo crítico $\left(\theta_{\text {crit }}\right)$. Por fim, se o ângulo de incidência excede o ângulo crítico, como na figura da direita, não há mais raio transmitido, e ocorre apenas a reflexão.
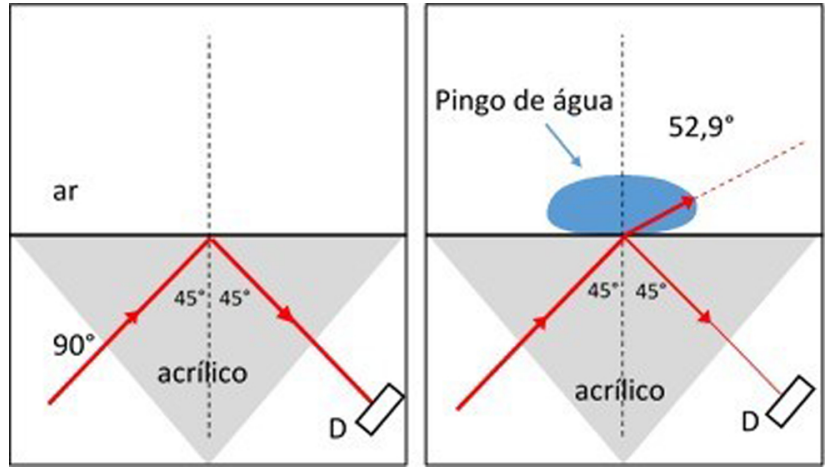

Figura 2: À esquerda, um raio de luz incide numa interface acrílico - ar. Esse ângulo é de $45^{\circ}$, maior que o ângulo limite de $41,8^{\circ}$, e então ocorre apenas reflexão, não existindo raio transmitido para o ar. Na figura da direita o segundo meio, em vez de ar, é água. O ângulo de incidência permanece o mesmo, $45^{\circ}$; mas dessa vez há um raio transmitido, sob um ângulo de $52,9^{\circ}$. O sinal recebido por um detector $D$ é máximo na figura da esquerda, e cai consideravelmente na figura da direita.

custo bastante razoável. Para esse ângulo, ocorre apenas reflexão, e não há raio transmitido para o segundo meio, o ar; ver a figura 2, à esquerda.

Em seguida, por meio de um conta gotas, é colocado um pingo de água no ponto onde o feixe de laser atinge o plano de separação acrílico - ar. Com isso, o segundo meio passa agora a ser a água, como na figura 2 , à direita. Nessas condições, passará a existir o raio refratado (ou transmitido), e ele fará um ângulo com a normal de aproximadamente $52,9^{\circ}$, valor que pode ser obtido por meio da equação (1).

É possível, por meio da teoria eletromagnética clássica, prever as intensidades do raio refletido e refratado; para o leitor interessado, alguns resultados desse cálculo são apresentados no apêndice $\mathrm{A}^{1}$ Se a intensidade do raio

\footnotetext{
1 O leitor também poderá "medir" essas intensidades através de um simulador, que pode ser baixado gratuitamente em https://phet.colorado.edu/pt_BR/simulation/bending-light. Para isso, basta ajustar o simulador para que o meio superior tenha um índice de refração igual a 1,5 (o acrílico, no texto), o meio inferior igual a 1,33 (a água), e ajustar o laser para um comprimento de onda de $650 \mathrm{~nm}$ (esse é o valor "default" do programa)
}

incidente for tomada como proporcional a $100 \%$, a intensidade do raio refletido também será idealmente de $100 \%$. Essa é a situação da figura 2, à esquerda. Para a água como segundo meio, a intensidade dos raios refletido e refratado dependerá do estado de polarização do raio incidente. Na situação de polarização menos favorável, ou seja, aquela em que menos luz passa para o segundo meio (polarização paralela ao plano de incidência), o raio refletido terá sua intensidade reduzida para (aproximadamente) 2\%, e o raio refratado, (também aproximadamente) $98 \%$, sempre supondo que não há perdas.

\section{Descrição do modelo para o sensor de chuva}

Nas imagens da figura 3 aparece o dispositivo experimental, que consiste de um painel em madeira $(18 \mathrm{~cm}$ $\times 18 \mathrm{~cm}$, medidas apenas indicativas) no qual é fixado um laser, orientado num ângulo de $45^{\circ}$ com a vertical. Há também um suporte que consiste de dois pinos (ou pregos), nos quais é apoiado o prisma (dois dos ângulos internos são de $45^{\circ}$, e o terceiro, de $90^{\circ}$, como na imagem). A abertura no painel permite que quem manipula o modelo possa pingar uma gota d'água no prisma sem obstruir a visão de quem visualiza essa ação. Por fim, o anteparo que aparece na imagem (feito em papel vegetal) permite a visualização, por parte da audiência (que pode ser eventualmente grande) do feixe refletido e do feixe transmitido (quando ele existe).

A sequência de uso do dispositivo é a seguinte: inicialmente, o laser é ligado, e pode-se notar no anteparo de papel vegetal que há apenas o raio refletido, dado que o ângulo de incidência $\left(45^{\circ}\right)$ supera o ângulo crítico para a

e um ângulo de incidência de $45^{\circ}$. O ajuste do ângulo pode ser feito por meio da ferramenta "transferidor". Logo após, basta selecionar a ferramenta de medida de intensidade, colocando-a no raio refratado, e depois no raio refletido. Os valores obtidos através do simulador são consistentes com os apresentados no texto e no apêndice 1. É bastante interessante propor, caso seja viável, a exploração desse simulador por parte dos alunos, que poderão, por exemplo, selecionar o ar como segundo meio, e depois selecionar a água, observando o que ocorre e fazendo medições. 


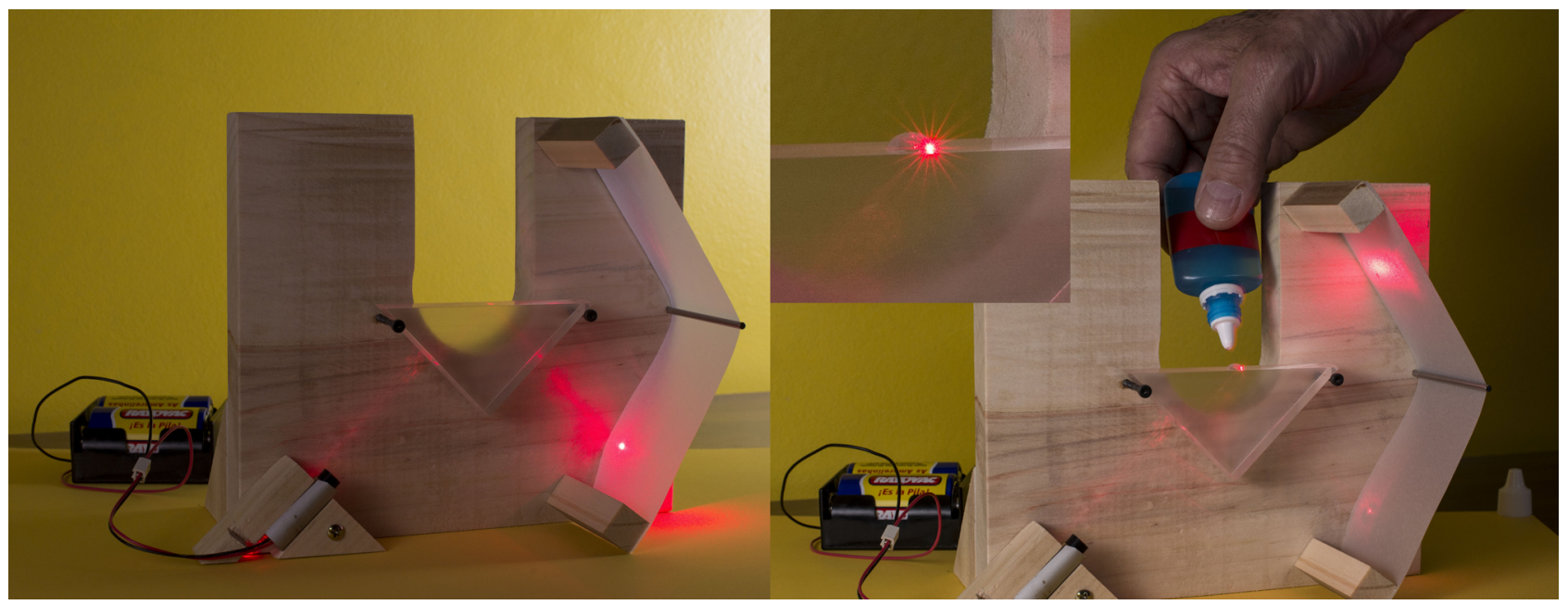

Figura 3: Considere a interface acrílico - ar da face superior, horizontal, do prisma, na imagem à esquerda. O feixe de laser incide nessa interface formando um ângulo de $45^{\circ}$ em relação à normal (veja também a figura 2), e assim é completamente refletido. Na imagem da direita, um pingo d'água faz com que a interface agora separe o acrílico da água, e o ângulo crítico (antes $41,8^{\circ}$ ) passa a ser $52,5^{\circ}$. Então, passa a existir um raio transmitido, e o raio refletido, que persiste, sob o mesmo ângulo, perde muito de sua intensidade inicial.

interface acrílico - ar $\left(41,8^{\circ}\right)$. Note que o raio incidente entra no prisma sem sofrer desvio, pois atravessa a interface ar - acrílico sob um ângulo de $0^{\circ}$, medido com a normal a essa interface. O mesmo ocorre quando o raio refletido abandona o prisma. Note também que, nessas condições, não há raio refratado.

A seguir, é pingada uma gota de água na superfície do prisma, no local de incidência do feixe de laser. Com isso, cumpre-se a condição da figura 2 , à direita; na figura 3 , também à direita, pode-se perceber a redução radical da intensidade do raio refletido, e a presença de um raio refratado, de grande intensidade. Mais precisamente, o raio refratado o é por duas vezes; na primeira, ele passa do acrílico para o interior da gota d'água, e na segunda, do interior da gota d'água para o ar, atingindo logo após o anteparo de papel vegetal, onde pode ser facilmente visualizado.

Se um detector ("D" na figura 2), conectado a um circuito eletrônico apropriado, for colocado de modo a receber o raio refletido, a presença eventual de água será detectada por conta da queda brusca da intensidade do raio refletido (que cai para $2 \%$, ou menos, de seu valor inicial), e, por exemplo, um limpador de para-brisa será acionado pelo circuito.

A fonte de luz empregada no dispositivo da figura 3 é um laser de diodo, de comprimento de onda igual a $650 \mathrm{~nm}$. Outros lasers, com outros comprimentos de onda, funcionariam igualmente bem, mas esse tipo de laser é o mais popular e o de menor custo. Os módulos de laser podem ser comprados no comércio informal, a um custo bastante acessível; os do tipo "chaveiro" possuem alimentação própria. Caso seja empregada uma alimentação externa, sugere-se uma fonte Arduíno, de 5 volts, ou mesmo pilhas de 1,5 volts (três, em série).
O prisma de acrílico também pode ser encontrado no comércio eletrônico: um kit com o prisma necessário para esse trabalho, mais uma lente convergente plana e uma lente divergente plana custa o equivalente a pouco mais de 50 Reais.

Por fim, a tira de papel vegetal, que aparece na figura 3 , permitirá que mesmo uma grande audiência visualize os raios refletido e refratado, sob diversos ângulos, o que torna o dispositivo utilizável em aulas com um número de alunos relativamente grande.

\section{Conclusões}

O "mote" que pode ser explorado aqui é o contraste entre uma física, cujos princípios eram conhecidos com alguma profundidade já no século XVI, com uma tecnologia, a do sensor de chuva automotivo, que em tempos recentes, é cada vez mais disseminada e pode ser encontrada em um número crescente de modelos de veículos automotivos. Essa possibilidade motiva bastante os estudantes, em especial pelo destaque que pode ser dado ao princípio físico subjacente, a reflexão interna total.

Sensores de chuva equipam alguns modelos de automóveis, são instalados no vidro frontal, que é em geral bastante inclinado, o que faz com que as gotas de chuva escorram, com algumas delas passando sobre o sensor. A frequência de passagem dessas gotas converte-se numa informação para o circuito eletrônico, e esse programará a passagem do limpador de para-brisa com maior ou menor frequência.

A motivação dos estudantes é mantida, mesmo que a eletrônica envolvida não seja explorada, como é o caso nesse artigo. É claro que, se algum estudante interessado, com algum conhecimento prévio de eletrônica, se dispuser 
a projetar e montar uma versão simplificada de um circuito acionador, ter-se-á aí uma excelente oportunidade de desenvolvimento de um projeto, a ser apresentado, por exemplo, em feiras de ciências.

Por fim, a eventual monotonia de uma aula expositiva sobre reflexão e refração poderá ser quebrada com a exploração desse dispositivo, o qual propiciará, por certo, um envolvimento maior dos estudantes, sob forma, em especial, de perguntas e contribuições as mais diversas.

\section{Agradecimento}

Os autores agradecem aos revisores da RBEF pelas valiosas contribuições e sugestões apresentadas.

\section{Material Suplementar}

O seguinte material suplementar está disponível online: Apêndice 1 - As equações de Fresnel

\section{Referências}

[1] E. Hecht, Optics (Addison-Wesley Pub, Massachusetts, 1974) $2^{\mathrm{a}}$ ed.

[2] D. Haliday, R. Resnick e J. Walker, Fundamentos de Física (LTC, Rio de Janeiro, 2010) v. 4, $9^{\mathrm{a}}$ ed.

[3] https://en.wikipedia.org/wiki/Rain_sensor.

[4] S. K. Byung, G. K. Young e S. H. Lee, Advanced Science and Technology Letters 141, 133 (2016). 